\title{
Polystyrene Supported AI(OTf) 3 : a Stable, Efficient, Selective, and Reusable Catalyst for Sulfonylation of Arenes with Sulfonic Acids
}

\author{
Kaveh Parvanak Boroujeni \\ Department of Chemistry, Shahrekord University, Shahrekord (115), Iran.E-mail: parvanak-ka@sci.sku.ac.ir \\ Received February 14, 2010, Accepted April 28, 2010

\begin{abstract}
Cross-linked polystyrene supported aluminium triflate (Ps-Al(OTf $)_{3}$ ) was found to be an efficient and chemoselective heterogeneous Lewis acid catalyst for the direct conversion of arenes to sulfones using sulfonic acids as sulfonylating agents. The solid acid catalyst is stable (as a bench top catalyst) and can be easily recovered and reused without appreciable change in its efficiency.
\end{abstract}

Key Words: Sulfonylation, Sulfones, Sulfonic acids, Aluminium triflate, Polystyrene

\section{Introduction}

Organosulfones are useful intermediates in a wide range of fields such as agrochemicals, ${ }^{1}$ pharmaceuticals, ${ }^{2,3}$ and polymers. ${ }^{4}$ In particular, aryl sulfones have received much attention as powerful anti-HIV-1 agents. ${ }^{5}$ They also possess high antifungal, antibacterial, and antitumoral activities. ${ }^{6,7}$ Aryl sulfones have been prepared by Friedel-Crafts sulfonylation of arenes using sulfonyl chlorides ${ }^{8-21}$ or by the condensation of arenes with sulfonic acids. ${ }^{22-30}$ The later method has the following advantages: more availability of starting materials (sulfonic acids are common precursors of sulfonyl chlorides), the reaction produces water as the only by-product, which meets recent requirement for environmentally benign processes, and the products are purer and the isolation of products is simple with no need of acid removal. However, only a few studies on the use of sulfonic acids as sulfonylating agents have been reported and many of these procedures are not quite successful as practical and general synthetic methods. For instance, Graybill reported polyphosphoric acid as a catalyst for the direct sulfonylation of arenes. ${ }^{22}$ However, polyphosphoric acid is a viscous liquid and is not easy to handle and the reaction suffers from low yields and long reactions times. $\mathrm{MeSO}_{3} \mathrm{H} / \mathrm{P}_{2} \mathrm{O}_{5}$ (as dehydrating agent) has been studied for the synthesis of sulfones using sulfonic acids. ${ }^{25}$ This method has certain disadvantages such as time consuming, thermal decomposition of reagent, and using a 10-fold excess of methansulfonic acid. Recently, it was also shown that $\mathrm{Fe}^{3+}$ montmorillonite, Nafion- $\mathrm{H}$, and $\mathrm{P}_{2} \mathrm{O}_{5} / \mathrm{Al}_{2} \mathrm{O}_{3}$ promote the sulfonylation of arenes using sulfonic acids. ${ }^{11,26,29}$ Although these methods are environmentally safe, the reactions have some limitations such as unsatisfactory yields, long reaction times, and reflux conditions. Sulfonylation of arenes using sulfonic acids without the need of any catalyst has been reported but in this method the reactions occur in the presence of 1.5 molar equivalents of $\mathrm{Tf}_{2} \mathrm{O}$ in $\mathrm{CH}_{3} \mathrm{NO}_{2}$ which results in a substantial amount of waste and in corrosion problems. ${ }^{30}$ In view of this, a reliable method for this useful reaction involving heterogeneous catalysts is in demand.

In a continuation of our ongoing program to develop environmentally benign methods using heterogeneous Lewis acid catalysts, we found that Ps-Al(OTf $)_{3}$ was a good catalyst for highly chemoselective dithioacetalization of carbonyl compounds. ${ }^{31}$ Along this line, we now wish to report that $\mathrm{Ps}-\mathrm{Al}(\mathrm{OTf})_{3}$ is also highly chemoselective catalyst for the sulfonylation of arenes using benzenesulfonic acid $\left(\mathrm{PhSO}_{3} \mathrm{H}\right), p$-toluenesulfonic acid $(\mathrm{TsOH})$, and methanesulfonic acid $\left(\mathrm{MeSO}_{3} \mathrm{H}\right)$ in solventfree conditions (Scheme 1).

\section{Experimental}

Chemicals were either prepared in our laboratory or were purchased from Merck and Fluka. Polystyrene (8\% divinylbenzene, prepared via suspension polymerization, polyvinylpyrrolidone $90 \mathrm{~K}$ as suspension agent, grain size range: 0.25 $0.6 \mathrm{~mm}$ ) was obtained from Iran Polymer and Petrochemical Institute. The capacity of the catalyst was determined by the Mohr titration method and atomic absorption technique using a Philips atomic absorption instrument. Reaction monitoring and purity determination of the products were accomplished by GLC or TLC on silica-gel polygram SILG/UV 254 plates. Gas chromatographic analysis was performed on Shimadzu GC. 14-A. IR spectra were run on a Shimadzu model 8300 FT-IR spectrophotometer. NMR spectra were recorded on a Bruker Advance DPX-300 spectrometer.

Preparation of Ps-Al(OTf) 3 . In a two necked round bottomed flask $(100 \mathrm{~mL})$ equipped with a reflux condenser, a solution of Ps- $\mathrm{AlCl}_{3}(3 \mathrm{gr}, 8 \% \mathrm{DVB})^{18}$ in Freon-113 $(50 \mathrm{~mL})$ was prepared. To the stirred solution was added dropwise $5 \mathrm{~mL}$ of triflic acid over a period of $2 \mathrm{~h}$, while mentioning a gentle reflux. The mixture was then refluxed for $12 \mathrm{~h}$. The polymer beads were filtered and washed with $\mathrm{CH}_{2} \mathrm{Cl}_{2}(50 \mathrm{~mL})$ and then with $\mathrm{Et}_{2} \mathrm{O}(50 \mathrm{~mL})$ and dried in a vacuum oven overnight to give Ps-Al(OTf $)_{3}$. The loading of $\mathrm{Al}(\mathrm{OTf})_{3}$ determined was $0.41 \mathrm{mmol} / \mathrm{gr}$.

Typical experimental procedure. In a round-bottomed flask (25 mL) equipped with a condenser and a magnetic stirrer a

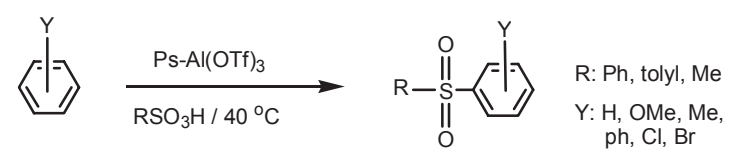

Scheme 1 
Table 1. Sulfonylation of arenes with sulfonic acids using Ps-Al(OTf ${ }_{3}{ }^{a}$

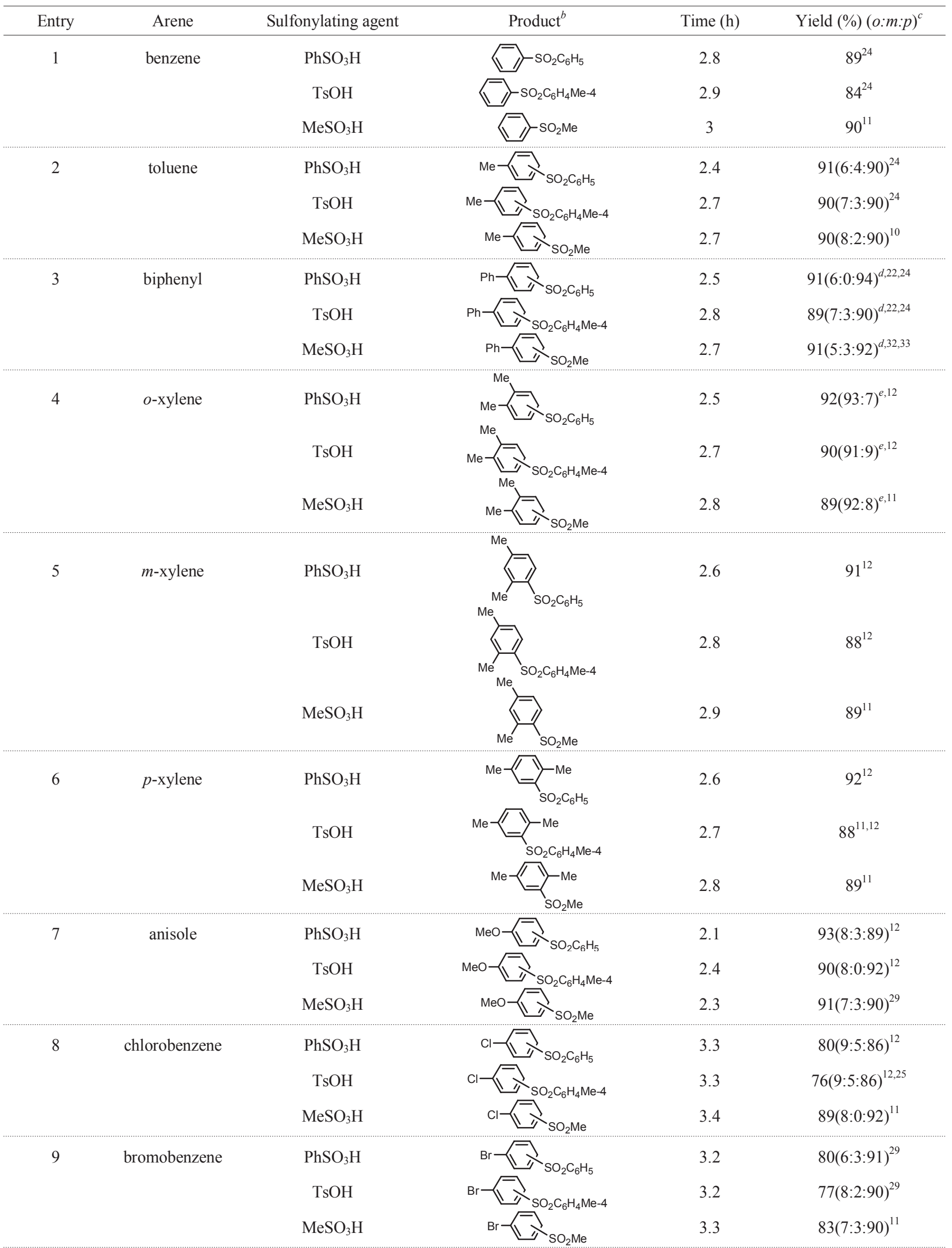


Table 1. Continued

\begin{tabular}{|c|c|c|c|c|c|}
\hline Entry & Arene & Sulfonylating agent & Product $^{b}$ & Time (h) & Yield (\%) $(o: m: p)^{c}$ \\
\hline \multirow[t]{3}{*}{10} & naphthalene & $\mathrm{PhSO}_{3} \mathrm{H}$ & & 3.8 & $89(10: 90)^{f, 12}$ \\
\hline & & $\mathrm{TsOH}$ & & 4 & $84(9: 91)^{f, 12}$ \\
\hline & & $\mathrm{MeSO}_{3} \mathrm{H}$ & & 4 & $85(10: 90)^{f, 32,34}$ \\
\hline \multirow[t]{3}{*}{11} & indole & $\mathrm{PhSO}_{3} \mathrm{H}$ & & 4.1 & $90^{d, 14,32}$ \\
\hline & & $\mathrm{TsOH}$ & & 4.3 & $81^{d, 14,32}$ \\
\hline & & $\mathrm{MeSO}_{3} \mathrm{H}$ & & 4.2 & $88^{d, 14,32}$ \\
\hline
\end{tabular}

${ }^{a} \mathrm{~A} 11$ reactions carried out at $40{ }^{\circ} \mathrm{C}$ in the absence of solvent, unless otherwise indicated. The molar ratio of the sulfonic acid: Ps- $\mathrm{Al}(\mathrm{OTf})_{3}$ is: $1: 0.1 .{ }^{b} \mathrm{All}$ products are known compounds and were identified by comparison of their physical and spectral data with those of the authentic samples. ${ }^{c}$ Yield refers to the mixture of isomeric products. Isomer distribution based on ${ }^{1} \mathrm{H}$ NMR study of crude sulfones. ${ }^{d}$ The reaction was performed at $80{ }^{\circ} \mathrm{C}$ in acetonitrile. ${ }^{e}$ Isomer distribution of 3,4-dimethylphenyl isomer to 2,3-dimethylphenyl isomer. ${ }^{f} \alpha: \beta$ ratio. The reaction was performed at $80{ }^{\circ} \mathrm{C}$ in acetonitrile.

solution of $m$-xylene $(10 \mathrm{mmol})$ and $\mathrm{TsOH}(7.5 \mathrm{mmol})$ was prepared. Ps-Al(OTf $)_{3}(0.75 \mathrm{mmol})$ was added to the solution and the reaction mixture was stirred magnetically at $40{ }^{\circ} \mathrm{C}$. Progress of the reaction was followed by TLC and GC. After completion of the reaction, the catalyst was filtered off and washed with $\mathrm{CH}_{2} \mathrm{Cl}_{2}$ or ether $(2 \times 15 \mathrm{~mL})$ and the filtrate was washed with $10 \% \mathrm{NaHCO}_{3}$ solution $(2 \times 10 \mathrm{~mL})$ and water $(10 \mathrm{~mL})$. The combined organic layers were dried over anhydrous $\mathrm{Na}_{2} \mathrm{SO}_{4}$, concentrated in vacuo, and the residue was recrystalized from $\mathrm{CH}_{2} \mathrm{Cl}_{2} / n$-hexane to give (2,4-dimethylphenyl)tolylsulfone as a white crystalline solid: Yield $88 \%$, mp $52-53{ }^{\circ} \mathrm{C}$ (lit., ${ }^{12} 51$ $52{ }^{\circ} \mathrm{C}$ ). The spent catalyst from sulfonylation reactions was washed with ether and used again without further drying. Representative examples of spectroscopic data are given below.

Di(p-tolyl)sulfone (Table 1, entry 2): ${ }^{1} \mathrm{H}$ NMR (300 MHz; $\left.\mathrm{CDCl}_{3}\right) \delta 2.31$ (s, $5.40 \mathrm{H}$, para isomer), $2.36(\mathrm{~s}, 0.18 \mathrm{H}$, meta isomer), 2.41 (s, $0.42 \mathrm{H}$, ortho isomer), $7.27(\mathrm{~d}, J=8.0 \mathrm{~Hz}, 4 \mathrm{H})$, $7.78(\mathrm{~d}, J=8.0 \mathrm{~Hz}, 4 \mathrm{H})$; IR (KBr) $1160,1315 \mathrm{~cm}^{-1}$.

(2,4-Dimethylphenyl)p-tolylsulfone (Table 1, entry 5): ${ }^{1} \mathrm{H}$ NMR (300 MHz; $\left.\mathrm{CDCl}_{3}\right) \delta 2.41(\mathrm{~s}, 3 \mathrm{H}), 2.43$ (s, 3H), 2.45 (s, $3 \mathrm{H}), 7.12$ (s, 1H), 7.24 (d, 1H), 7.80 (d, 2H), 7.78 (d, 2H,), 8.09 (d, 1H); IR (KBr) 1157, $1315 \mathrm{~cm}^{-1}$.

(Chlorophenyl)methylsulfone (Table 1, entry 8): ${ }^{1} \mathrm{H}$ NMR $\left(300 \mathrm{MHz} ; \mathrm{CDCl}_{3}\right) \delta 2.95$ (s, $2.76 \mathrm{H}$, para isomer), 3.19 (s, $0.24 \mathrm{H}$, ortho isomer), 7.39-8.11 (m, 4H); IR (film) 1156, 1318 $\mathrm{cm}^{-1}$.

Napthyltolylsulfone (Table 1, entry 10): ${ }^{1} \mathrm{H}$ NMR (300 MHz; $\left.\mathrm{CDCl}_{3}\right) \delta 2.26$ (s, $2.73 \mathrm{H}, \beta$-isomer), 2.28 (s, $0.27 \mathrm{H}, \alpha$-isomer), $7.28(\mathrm{~m}, 2 \mathrm{H}), 7.51-7.64(\mathrm{~m}, 2 \mathrm{H}), 7.80-8.16(\mathrm{~m}, 5 \mathrm{H}), 8.55(\mathrm{~d}$, $J=8.6 \mathrm{~Hz}, 1 \mathrm{H}), 8.71(\mathrm{~d}, J=8.5 \mathrm{~Hz}, 1 \mathrm{H})$.

3-(4-Methylphenylsulfonyl)-1 $\boldsymbol{H}$-indole (Table $\mathbf{1}$, entry 11): $\left.1 \mathrm{H} \mathrm{NMR} \mathrm{(300} \mathrm{MHz,} \mathrm{CDCl}_{3}\right) \delta 2.25(\mathrm{~s}, 3 \mathrm{H}), 6.81-6.90(\mathrm{~m}$, 4H), 7.07-7.19 (m, 2H), 7.27-7.31 (m, 2H), 7.49 (d, $1 \mathrm{H}, J=8.0$ $\mathrm{Hz}$ ), 8.19 (brs, NH); IR (KBr) 3330, 1582, 1450, 1388, 1299 , $1230,1147,1097,758 \mathrm{~cm}^{-1}$.

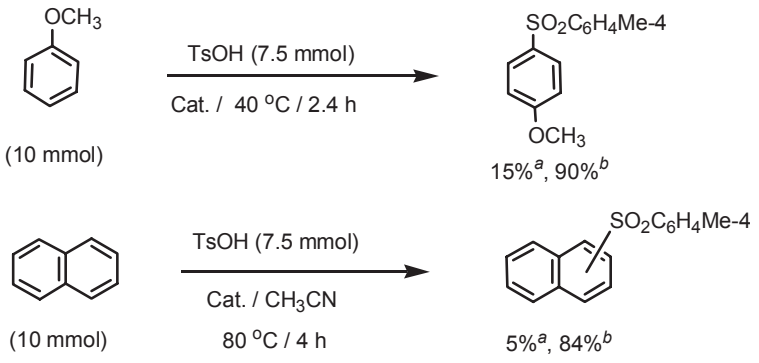

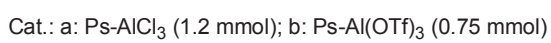

\section{Scheme 2}

\section{Results and Discussion}

Ps-Al(OTf $)_{3}$ was prepared by the exchange reaction between cross-linked polystyrene supported $\mathrm{AlCl}_{3}\left(\mathrm{Ps}_{\mathrm{S}}-\mathrm{AlCl}_{3}\right)$ and triflic acid in Freon-113 under reflux conditions. Using catalytic amounts of this catalyst in the sulfonylation of arenes with $\mathrm{PhSO}_{3} \mathrm{H}, \mathrm{TsOH}$, and $\mathrm{MeSO}_{3} \mathrm{H}$ as sulfonylating agents high to excellent yields of product are obtained at $40{ }^{\circ} \mathrm{C}$ (Table 1). The optimum molar ratio of $\mathrm{Ps}-\mathrm{Al}(\mathrm{OTf})_{3}$ to sulfonylating agent was $0.1: 1$. The aromatic compounds act as both the substrate and the solvent. From the results, it is clear that Ps-Al(OTf $)_{3}$ is capable of catalyzing not only the sulfonylation of activated arenes but also that of weakly deactivated arenes (entries 1-9). The methodology showed the excellent positional selectivity as the para substituted product was formed exclusively. Further the improvement in regioselectivity was also observed in sulfonylation of naphthalene (entry 10). The sulfonylation of indole with sulfonic acids in the presence of Ps-Al(OTf $)_{3}$ was also studied and the corresponding 3-arylsulfonyl indoles were obtained in $81-90 \%$ yields (entry 11 ). No $N$-substituted products were observed under these reaction conditions. Sulfonylation of highly deactivated arenes such as nitrobenzene and 1,2-di- 


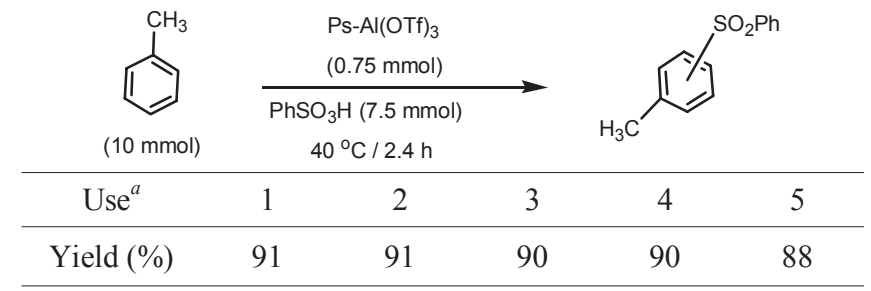

${ }^{a}$ Recovered catalyst was used successively (Use $2,3, \ldots$ ).

Scheme 3

chlorobenzene failed. Side product formation was not observed in the reactions we have studied. Ps- $\mathrm{Al}(\mathrm{OTf})_{3}$ was stable under the reaction conditions and there is no leaching of acid moieties during reactions. Steric crowding of supported catalyst influences positional selectivity (isomer distribution) observed in the sulfonylation of aromatic compounds.

It is important to note that $\mathrm{Ps}-\mathrm{Al}(\mathrm{OTf})_{3}$ shows more catalytic activity than $\mathrm{Ps}_{\mathrm{S}} \mathrm{AlCl}_{3}$ in sulfonylation of aromatic compounds with sulfonic acids (Scheme 2). ${ }^{18}$

When Ps-Al(OTf $)_{3}$ was used as catalyst for sulfonylation reactions, no band corresponding to $-\mathrm{SO}_{2}$ stretching in the IR spectrum of Ps-Al(OTf) 3 was observed after the reactions in either the presence or absence of substrate, indicating that polystyrene itself does not undergo sulfonylation under experimental condition used. Probably sulfonylation reactions are not favored with $\mathrm{Ps}-\mathrm{Al}(\mathrm{OTf})_{3}$ as a $\pi$ complex is formed between polystyrene and $\mathrm{Al}(\mathrm{OTf})_{3}$.

To find out whether there are any possibility to exchange between OTf and sulfonic acid used as sulfonylating agent, $\mathrm{Ps}-\mathrm{Al}(\mathrm{OTf})_{3}$ was added to a solution of TsOH and nitrobenzene and the mixture was stirred at $40{ }^{\circ} \mathrm{C}$ for $4 \mathrm{~h}$. Then, the catalyst was filtered off and the filtrate was analyzed for its $\mathrm{TfOH}$ content, which showed a negligible release of $\mathrm{TfOH}^{35}$ The filtrate was found to be inactive for the sulfonylation reaction. Also, the recovered solid catalyst (from the above reaction mixture) and fresh Ps-Al(OTf) ${ }_{3}$ have the same IR spectrum and show absorption peaks due to the triflate groups at 1245 - 1275, 1190, 1025 , and $780 \mathrm{~cm}^{-1} .^{31}$ These observations indicate that no exchange occurs between OTf and sulfonic acid used as sulfonylating agent.

Ability to recycling of Ps-Al(OTf $)_{3}$ is a notable feature, since the catalyst was recovered and reused five times for the preparation of sulfones without significant decrease in its efficiency (Scheme 3). The capacity of the catalyst after five uses was $0.40 \mathrm{mmol} \mathrm{Al}(\mathrm{OTf})_{3}$ per gram.

\section{Conclusion}

In conclusion, we have developed the use of $\mathrm{Ps}-\mathrm{Al}(\mathrm{OTf})_{3}$ as an inexpensive, easy to handle, non-corrosive, reusable, and environmentally benign catalyst for the sulfonylation of aromatic compounds. High chemoselectivity, mild and solvent free conditions, easy workup, short reaction times, and high to excellent yields are other obvious advantages of the present method.

Acknowledgments. The author thanks the Research Council of Shahrekord University for partial support of this work.

\section{References}

1. Michaely, W. J.; Kraatz, G. W. US Patent 4780127, 1988 (CAN: 1989, 111, P 129017a).

2. Padwa, A.; Bullock, W. H.; Dyszlewski, A. D. J. Org. Chem. 1990, $55,955$.

3. Block, E. Angew Chem., Int. Ed. Engl. 1992, 31, 1135.

4. Mackinnon, S. M.; Wang, J. Y. Macromolecules 1998, 31, 7970.

5. McMohan, J. B.; Gulakowsky, R. J.; Weislow, O. S.; Schoktz, R. J.; Narayanan, V. L.; Clanton, D. J.; Pedemonte, R.; Wassmundt, F. W.; Buckheit, R. W.; Decker, W. D.; White, E. L.; Bader, J. P.; Boyd, M. R. Antimicrob. Agents Chemother. 1993, 37, 754.

6. Richards, I. C.; Thomas, P. S. Pestic. Sci. 1990, 30, 275.

7. Dinsmore, C. J.; Williams, T. M.; O’Neill, T. J.; Liu, D.; Rands, E.; Culberson, J. C.; Lobell, R. B.; Koblan, K. S.; Kohl, N. E.; Gibbs, J. B.; Oliff, A. I.; Graham, S. L.; Hartman, C. D. Bioorg. Med. Chem. Lett. 1999, 9, 3301.

8. Jensen, R.; Goldman, G. In Friedel-Crafts and Related Reactions; Olah, G., Ed.; Wiley Interscience: New York, 1964; Vol. III, p 1319.

9. Simpkins, N. S. Sulfones in Organic Synthesis; Pergamon Press: Oxford, 1993.

10. Olah, G. A.; Kobayashi, S.; Nishimura, J. J. Am. Chem. Soc. 1973, $95,564$.

11. Choudhary, B. M.; Chowdari, N. S.; Kantam, M. L. J. Chem. Soc., Perkin Trans 1 2000, 16, 2689.

12. Singh, R. P.; Kamble, R. M.; Chanda, K. L.; Saravanan, P.; Singh, V. K. Tetrahedron Lett. 2001, 57, 241.

13. Frost, C. G.; Hartley, J. P.; Whittle, A. J. Synlett 2001, 6, 830.

14. Yadav, J. S.; Reddy, B. V. S.; Krishna, A. D.; Swamy, T. Tetrahedron Lett. 2003, 44, 6055.

15. Garzya, V.; Forbes, I. T.; Lauru, S.; Maragni, P. Tetrahedron Lett. 2004, 45, 1499.

16. Singh, D. U.; Singh, P. R.; Samant, S. D. Tetrahedron Lett. 2004, 45,9079 .

17. Alexander, M. V.; Khandekar, A. C.; Samant, S. D. J. Mol. Catal. A: Chem. 2004, 223, 75.

18. Parvanak Boroujeni, K.; Tamami, B. Catal. Commun. 2007, 8, 1191.

19. Bahrami, K.; Khodei, M. M.; Shahbazi, F. Tetrahedron Lett. 2008, 49, 3931 .

20. Cooke, M.; Clark, J.; Breeden, S. J. Mol. Catal. A: Chem. 2009, $303,132$.

21. De Noronha, R. G.; Fernandes, A. C.; Romao, C. C. Tetrahedron Lett. 2009, 50, 1407.

22. Graybill, B. M. J. Org. Chem. 1967, 32, 2931.

23. Eaton, P. E.; Caqrlson, G. R.; Lee, J. T. J. Org. Chem. 1973, 38, 4071.

24. Sipe, H. J.; Clary, D. W.; White, S. B. Synthesis 1984, 283.

25. Ufda, M.; Uchiyama, K.; Kano, T. Synthesis 1984, 323.

26. Olah, G. A.; Mathew, T.; Parakash, G. K. S. Chem. Commun. 2001, 1696.

27. Mirjalali, M. B.; Zolfigol, M. A.; Bamoniri, A.; Khazdooz, L. Bull. Korean Chem. Soc. 2003, 24, 1009.

28. Li, H.-Z.; Xiao, L.-W.; Li, H.-Y.; Wang, K.-F.; Li, X. J. J. Chem. Res. (S) 2003, 493.

29. Hajipour, A. R.; Zarei, A.; Khazdooz, L.; Pourmousavi, S. A.; Mirjalili, B. B. F.; Ruoho, A. E. Phosphorus, Sulfur, and Silicon 2005, 180, 2029.

30. Alizadeh, A.; Khodaei, M. M.; Nazari, E. Tetrahedron Lett. 2007, 48, 6805 .

31. Parvanak Boroujeni, K.; Massah, A. R. React. Funct. Polym. 2006, $66,1126$.

32. Dictionary of Organic Compounds, 6th ed.; Chapman and Hall: London, 1996.

33. Beaulieu, C.; Guay, D.; Wanga, Z.; Evans, D. A. Tetrahedron Lett. 2004, 45, 3233.

34. Katritzky, A. R. J. Org. Chem. 1986, 51, 4914.

35 . The content of TfOH was measured by titration method and checked by extraction-photometric method: Harvey, D. T. Modern Analytical Chemistry; McGraw-Hill:Dubuque, 2000; Dorogova, V. B.; Zhurba, O. M.; Rozhanskaya, A. V.J. Anal. Chem. 2009, 64, 674. 